\title{
Vibration Induced Damage to Existing Masonry Structures Caused by Heavy Construction Activities
}

\author{
M.I.M.R Khan and H.P Sooriyaarachchi
}

\begin{abstract}
Use of heavy construction machineries close to existing structures is complained for cracking of un-reinforced masonry structures. Domestic houses, which are built with un-reinforced masonry, are particularly vulnerable for cracking due to construction induced vibration. To limit the structural damage to masonry construction, Environmental Authority has come up with velocity $2 \mathrm{mms}^{-1}$ and frequency range of (10-50) $\mathrm{Hz}$ as the safe vibration level for masonry constructions. However, complaints of damages to masonry structures still exist at these threshold levels. Apart from masonry type, vibration impact also depends on the number of openings, shape and size of the openings and the fixity condition of the wall panel. In this study, wall panels with different openings that have sustained damages at the threshold vibration level during the construction activitics of Colombo - Matara express way are analysed to evaluate the relevance of current threshold limit and determine the influence of the opening on the dynamic response of the wall panels.

Dynamic finite element analysis conducted on the selected wall panels; based on actual vibration data collected from site during construction activities, strongly indicates that there is a direct correlation between stress pattern of the dynamic analysis and the actual crack pattern observed on the panel. Further analysis confirmed that the vibration has resulted in stress combination outside the experimentally establish failure surface for brick masonry confirming that the current limit is inadequate to safe guard against masonry cracking.
\end{abstract}

Keywords: Masonry construction, Construction induced vibration, Dynamic finite element analysis, Failure surface of masonry units.

\section{Introduction}

Masonry constructions are designed to beat vertical loading and are generally very weak in tension[1]. Un-reinforced masonry is vulnerable to crack under applied tensile stresses. Number of sources such as lateral loading by wind and vibration can induce tensile stresses on masonry panels. There are number of claims by the residents along the Colombo-Matara highway, that heavy machineries like vibratory roller used in soil compaction and various construction activities like blasting, and pile driving close to existing masonry structures is directly responsible for masonry cracking. Pre and post crack surveys carried out also indicate strong link between the vibration levels and masonry cracking.

In construction induced vibrations, severity of the vibration effect at the recipient depends on the distance from the source, the soil conditions and the magnitude and frequency of the source vibration. The effects of vibration broadly range from serious disturbance of working conditions for sensitive devices and people to visible structural damage. It is often difficult to relate structural defect to vibration as the relationships are complex to establish. For example, it is relatively easy to blame vibration due to pile driving for defects in nerby masonry strcutre but it is hard to establish masonry defects due to foundations settlements resulting from vibrations of loose soil that may occur far from the source.

Fig 1 shows possible sources of significant vibration. These sources generate $S$ (surface) and $\mathrm{P}$ (pressure) wave in the ground and it is the surface waves that cause the substantial damage to masonry structures [2][3]. The effect of construction vibration is a sensitive issue. According to human perception and psychology, construction vibration are the causes of all damage in structures, however in reality majority of vibration effect from constructon activities is negligible [2][3]. Therefore, it is very important to quantify the vibration levels and determine the structural effects of construction induced vibration. Like many other institution, Environmental

M.I.M.R Khan, BSc.Eng.(Hons) Graduate Engineer. Eng. (Dr.) H.P. Sooriyaarachchi, C. Eng., MIE (Sri Lanka), B.Sc. Eng. (Moratuwa), M.Eng. (Tokyo), PhD. (Shefficld), Senior Lecturer in Civil and Environmental Enginecring, Faculty of Engineering. Unizersily of Ruhuna, Hapugala, Galle. 


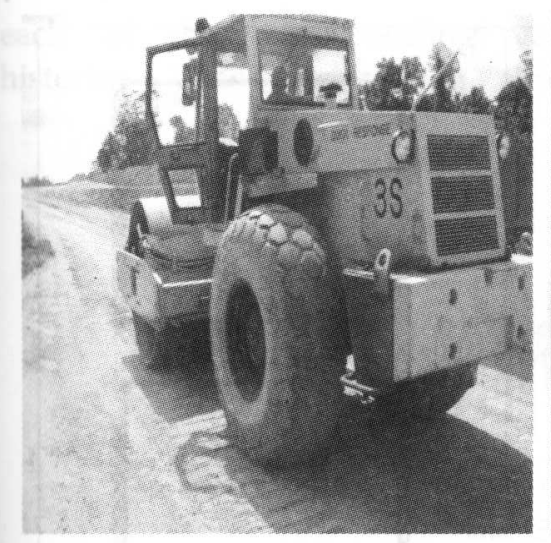

Compaction using vibrating

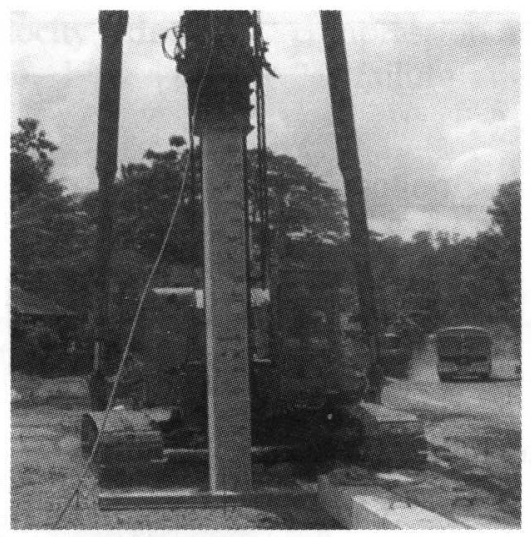

Pile driving

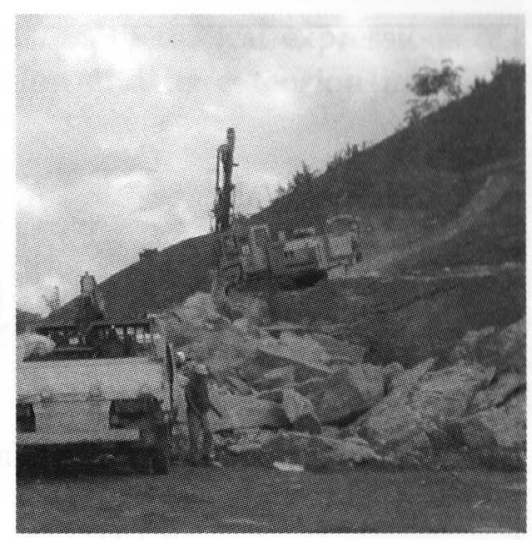

Blasting

Fig. 1 Possible sources of construction vibration

Authority of Sri Lanka have stipulated maxium velocity of $2 \mathrm{mms}^{-1}$ and frequency between 10$50 \mathrm{~Hz}$ as the permissible level of vibration to prevent damages to existing masonry stuctures[4] [5][ 6]. However, there are still complinats on the current limits to prevent masonry cracking.

Appropriateness of a single limit for strucutral damage of all types of masonry structures are often questioned. For example the dynamic behaviour of 9 " thick burnt clay brick masonry is expected to be different to $41 / 2^{\prime \prime}$ thick burnt clay brick masonry and $41 / 2^{\prime \prime}$ thick block masonry. In addition to the thickness of the wall and the type of masonry, boundary conditions of walls and the shape and size of an opening can influence vibration limit for masonry unit. In this study, wall panels with different opening that have actually been complained of having sustained damages at the applied vibration were analyzed to find out the influence of opening on the masonry cracking. Vibration histories used were within the environmental authority's prescribed limits and were recorded at the recipient during the construction activity.

\section{Methodology}

Fig. 2 shows selected wall panels that have suffered cracking due to construction induced vibration. Normally, Vibration is recorded about three perpendicular axes. Fig. 3 shows a vibration record (velocity time history) about one of the axes due to construction activities at recipient, complained of masonry damage. This particular vibration record depicted in the Fig. 3 has a maximum velocity close to $2 \mathrm{mms}^{-1}$ and a frequency close to $50 \mathrm{~Hz}$ both of which are close to the upper bound of the safe vibration limit recommended by environmental authority. SAP 2000 was selected conduct the dynamic analysis of the wall panel and it required vibration data fed in the form of acceleration history rather than velocity history [12]. This required converting the velocity history to acceleration history. As acceleration is the first derivative of the velocity, conversion is possible once velocity wave form is defined by any differentiable form. Whether the applied vibration can crack the masonry is then found by comparing the resulted stress combinations with the experimentally determined failure surface for masonry. All the selected panels were further studied under static loading to confirm that the experimentally establish failure surface is realistic and the resulted stresses combination under static loading fall within the failure surface.

\subsection{Velocity and acceleration history}

Dots in Fig. 3 are the source data, velocity vs. time recorded at the recipient. These data are from GSMB (Geological Survey and Mining Bureau) who were responsible for recording vibrations due to construction activities along the Colombo-Matara highway. It is learned that vibration were measured and records were maintained for all the building in the vicinity of the Colombo-Matara highway and owners were compensated based on whether the vibration level fall with in or outside the recommended limit of the environmental authority. Further more pre and post crack investigation of the building is also kept along with the vibration record during the construction activity. In the conversion of velocity time history to acceleration history, velocity time record needs to be approximated by a mathematical function. This was possible with spline line function 


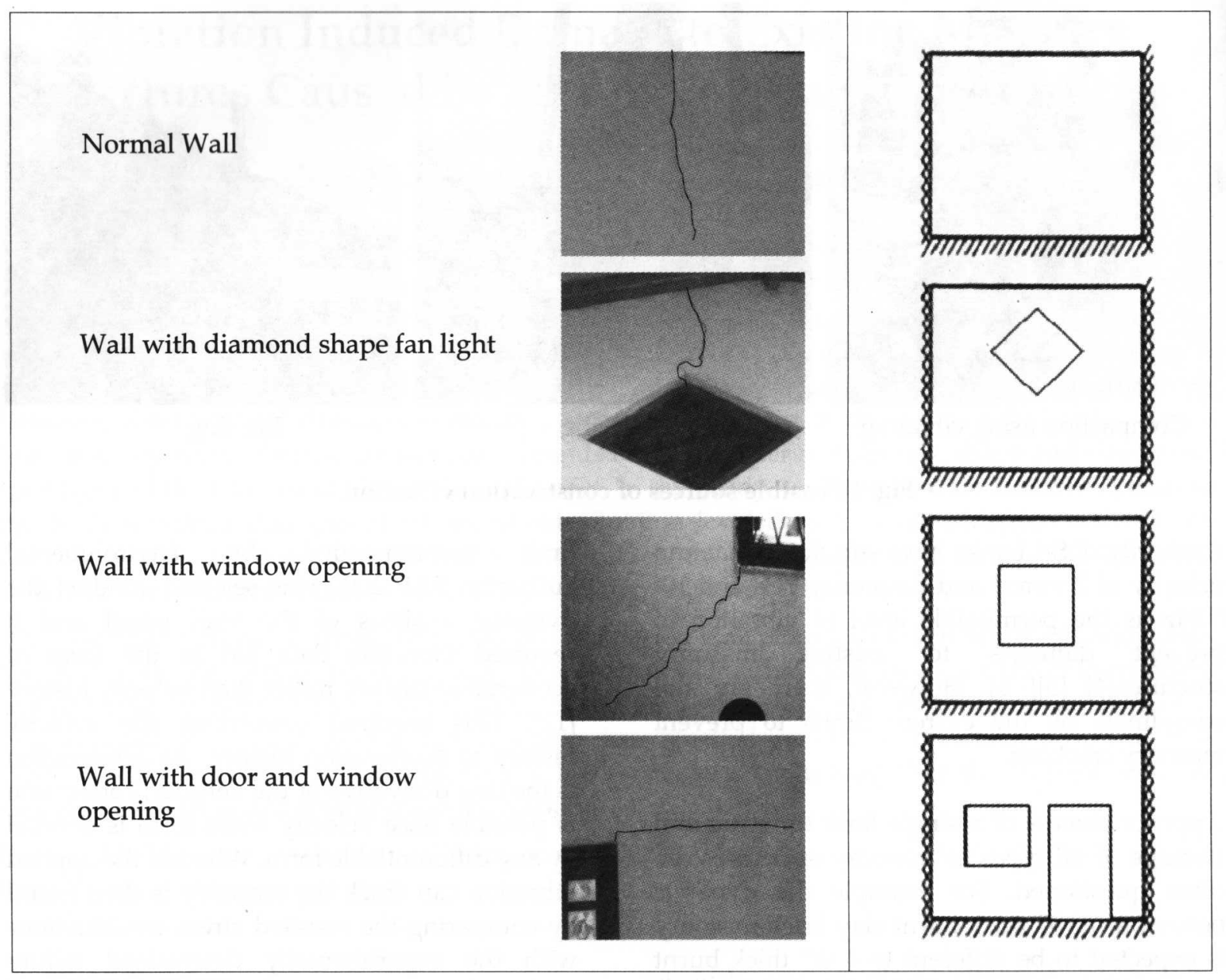

Fig. 2: Selected wall panels and their idealisation for dynamic analysis

available in MATLAB [13]. Spline line is a series of forth order polynomial functions that can be used to approximate velocity waveform from the dot points of GSMB records of velocity vs. time records. With spline line approximation, it
Continuous line in the Fig 3 is the spline line approximation of the recorded velocity history. Directions of the three perpendicular velocity records are known as transverse, vertical and longitudinal directions. Spline line

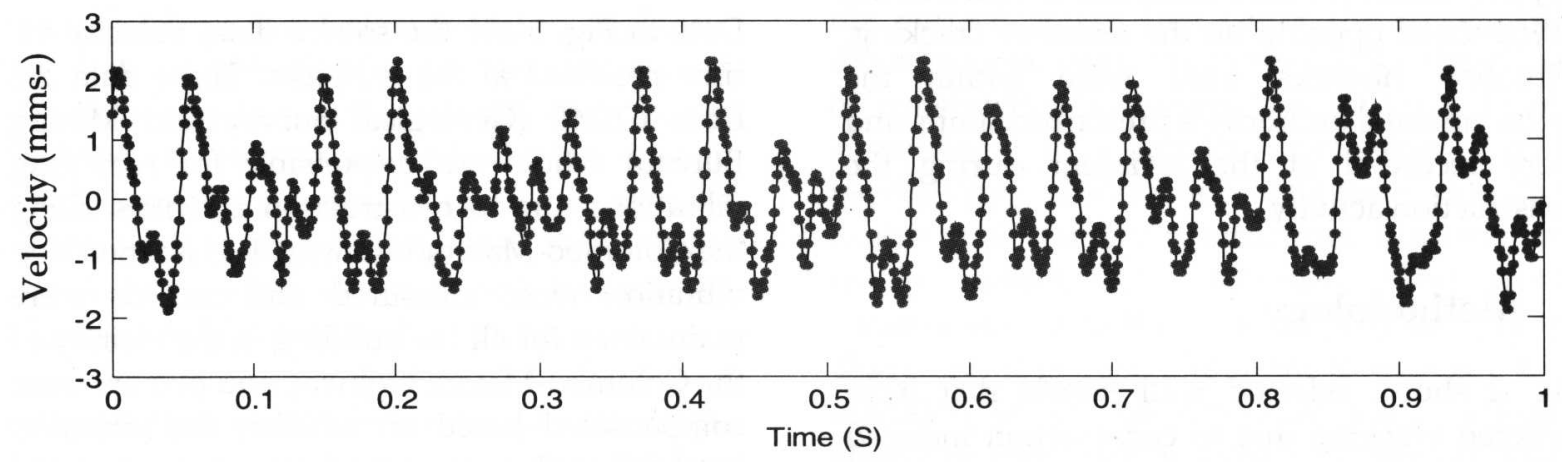

Fig. 3: Velocity time history recorded at the recipient and approximate spline line connecting data points

was possible to define the velocity wave form that passes through all the data points. However it must be mentioned that spline line is not just one function, it is series of fourth order polynomial functions concatenated to represent the data set as closely as possible. approximation of these data sets along with recorded data points in each of the three directions are shown in the left of Fig. 4. The accelerations about the three perpendicular directions which are derived by the first derivations of the velocities are shown next to 
aach of the corresponding velocity time histories. With acceleration time histories compression axis. Mathematical expressions of 2D failure envelop and its extension into 3D

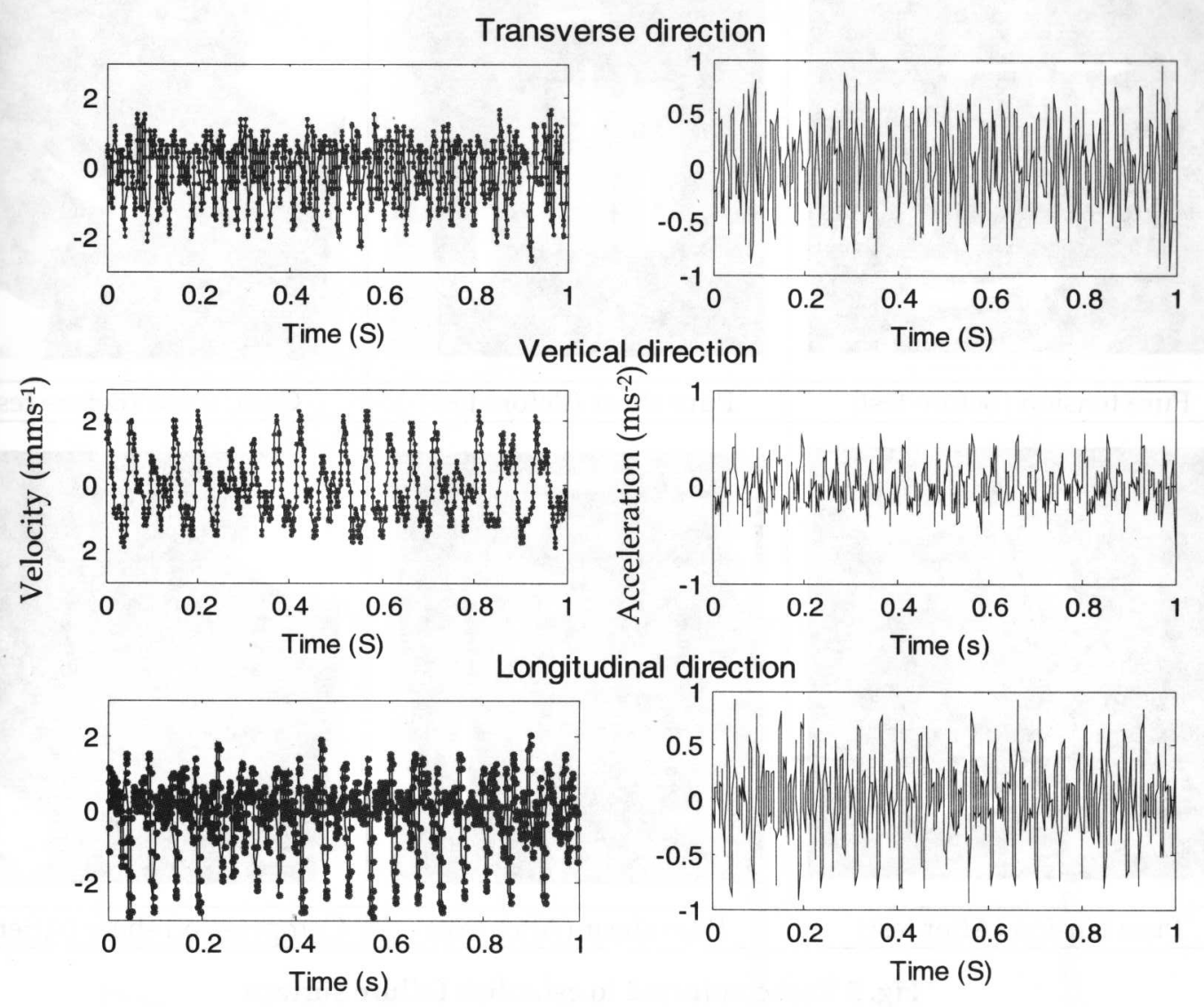

Fig. 4: Velocity histories converted into acceleration history

known, it is now possible to perform dynamic analysis of the wall panel. However, it is still too early to conclude whether the resulted stress combinations are capable of cracking the masonry unit. Establishment of the failure envelop to determine cracking is explained in the next section.

\subsection{Establishment of failure surface}

Failure surface for typical masonry units was established by calibrating an existing model for stress transfer between cracks [7][8][9][10]. Calibration was done by actual experiments on masonry under different loading namely; pure tension, pure shear and compression shear.

Fig. 5 show the three experiments (tension, shear, and compression shear) conducted to calibrate the failure envelop. Fig. 6 shows the 2D failure envelop derived based on tests conducted on the interface between the mortar and bricks.

Failure envelop in 2D is extended to 3D by revolving the $2 \mathrm{D}$ envelop about the tension and failure surface is given below. Fig. 7 shows the 3D paraboloid failure surface.

$$
\begin{aligned}
& \sigma_{21}^{2}-\left(C-\sigma_{11} \tan (\phi)\right)^{2}+(C-\chi \tan (\phi))^{2}=0 \\
& \sigma_{13}^{2}+\sigma_{12}^{2}-\left(C-\sigma_{11} \tan (\phi)\right)^{2}+(C-\chi \tan (\phi))^{2}=0 \\
& C-\text { Cohesion or Coefficient of inter locking } \\
& \chi-\text { Tension cut off, } \phi \text { - Angle of internal friction }
\end{aligned}
$$

\section{Analysis of typical wall panel}

SAP 2000 is used for both static and dynamic analysis of the wall panels. Wall panels are modelled using shell elements. The young's modulus of the masonry is taken as $4 \mathrm{GPa}$. (Actual analysis is done for different stiffness values between $0.5 \mathrm{GPa}-5 \mathrm{GPa}$. Although the average Young's modulus of unplastered masonry is around $1 \mathrm{GPa}$, the initial response of masonry, with applied plaster layers, is found significantly stiff before cracking). Further, the masonry units are assumed to behave as linear elastic continuum. This assumption has its limitations for modelling masonry brick walls as masonry is anisotropic material. Despite its limitations, it is expected that the assumption is 


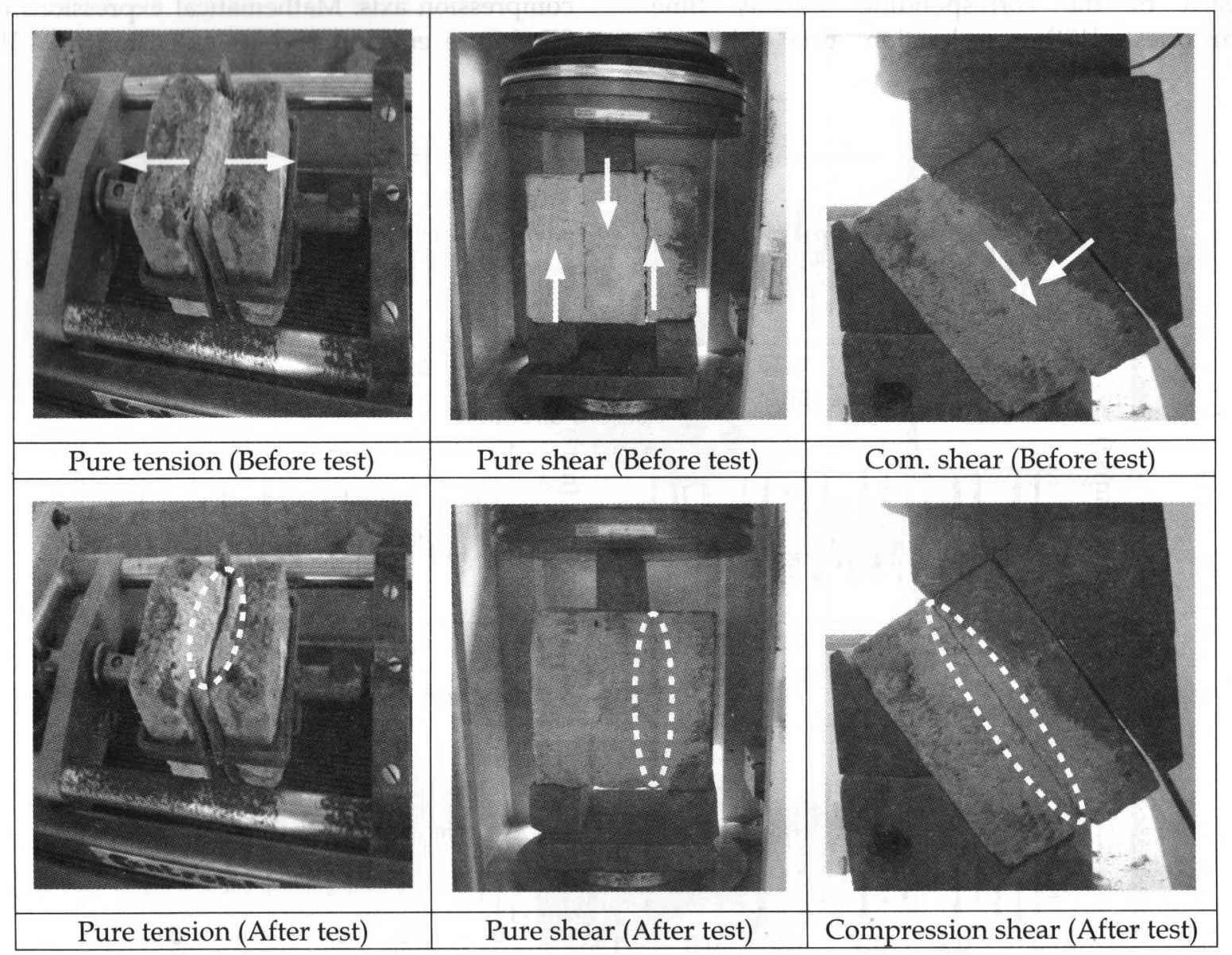

Fig. 5 Test conducted to establish failure surface

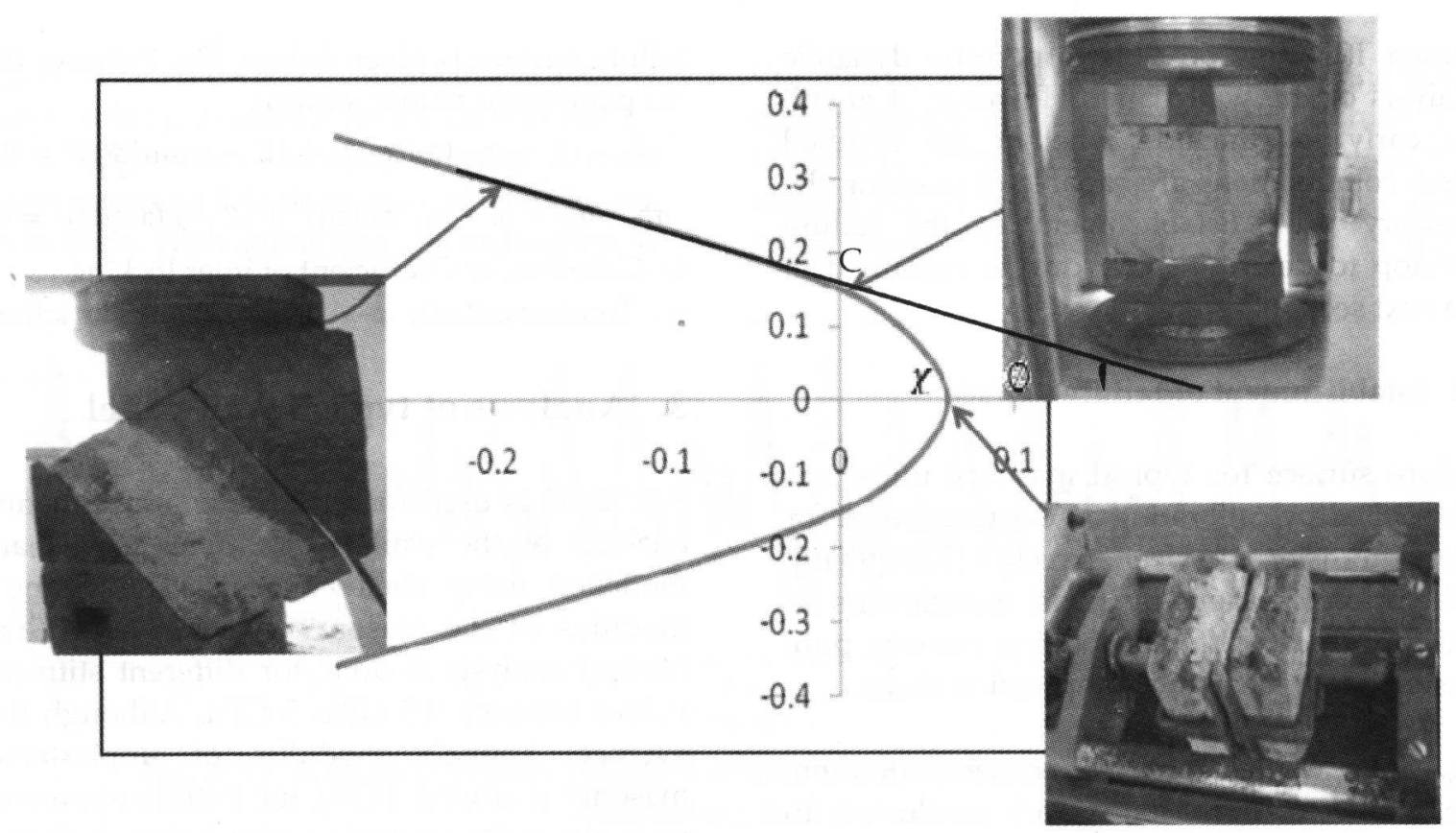

Fig. 6 Establishment of parabolic failure envelop

reasonable to establish stress combinations before cracking and that the masonry behave in linear elastic until cracking.
Fig. 8 shows the typical wall panel of single storied building under consideration and the structural idealization of it for the static and dynamic analysis. Wall intersections 
perpendicular to the direction of the plane of the wall and the connection at the foundation level is considered fixed whilst the top end is considered free in the analysis. construction induced vibration is considered first. Fig. 9 shows stress patterns both under static and dynamic loading of the wall panel. As the building is single storied, only nominal load from the roof is considered for static
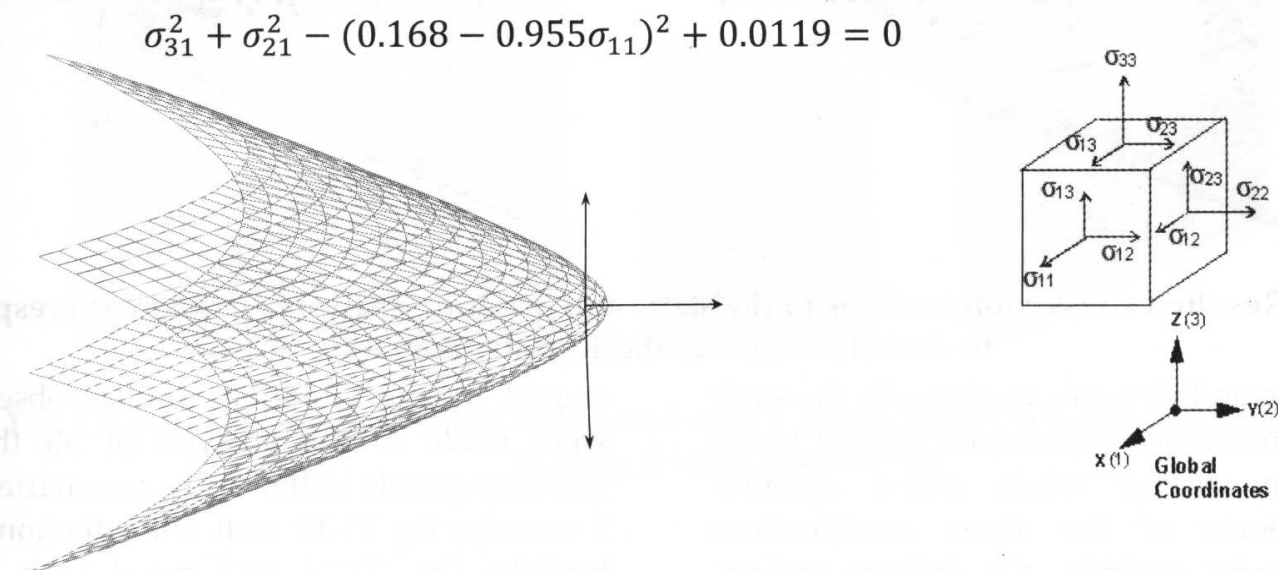

Fig. 7: 3D extension of the 2D failure surface (achieved by revolving the 2D surface)

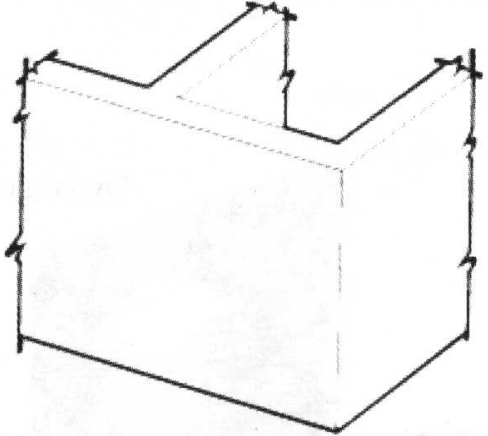

(a)Wall panels with intersecting walls at the ends

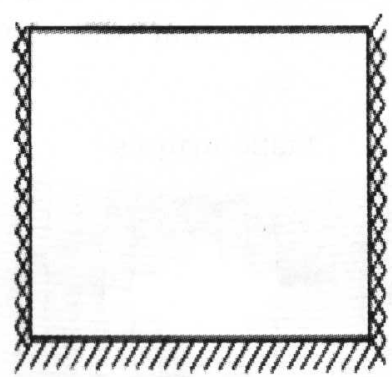

(b) Structural idealisation

Fig. 8: Idealisation of the wall panel for the dynamic analysis

\section{Results}

Results of static and dynamic analysis of the wall panel without opening which is claimed to have sustained vertical crack due to analysis. Dynamic analysis is based on the corresponding recipient acceleration history which is blamed for the masonry cracking. Fig.10 shows the failure surface and stress combination at various points of the wall both
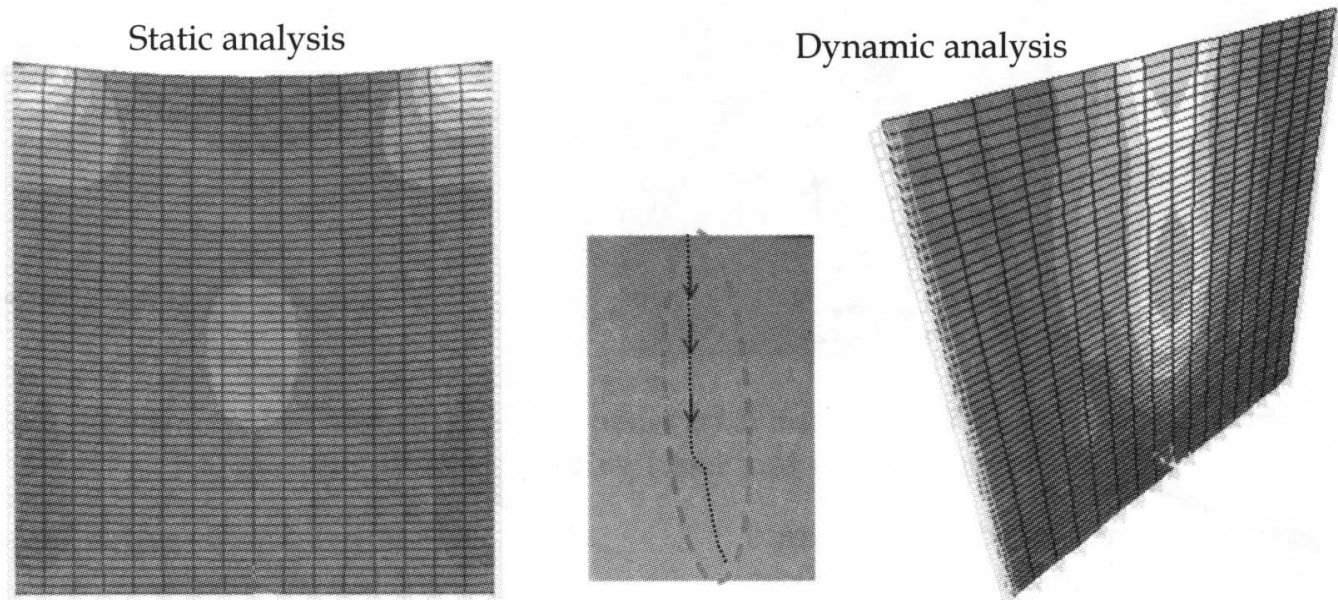

Fig. 9: Principal stress patterns of static and dynamic analysis (solid wall panel) 

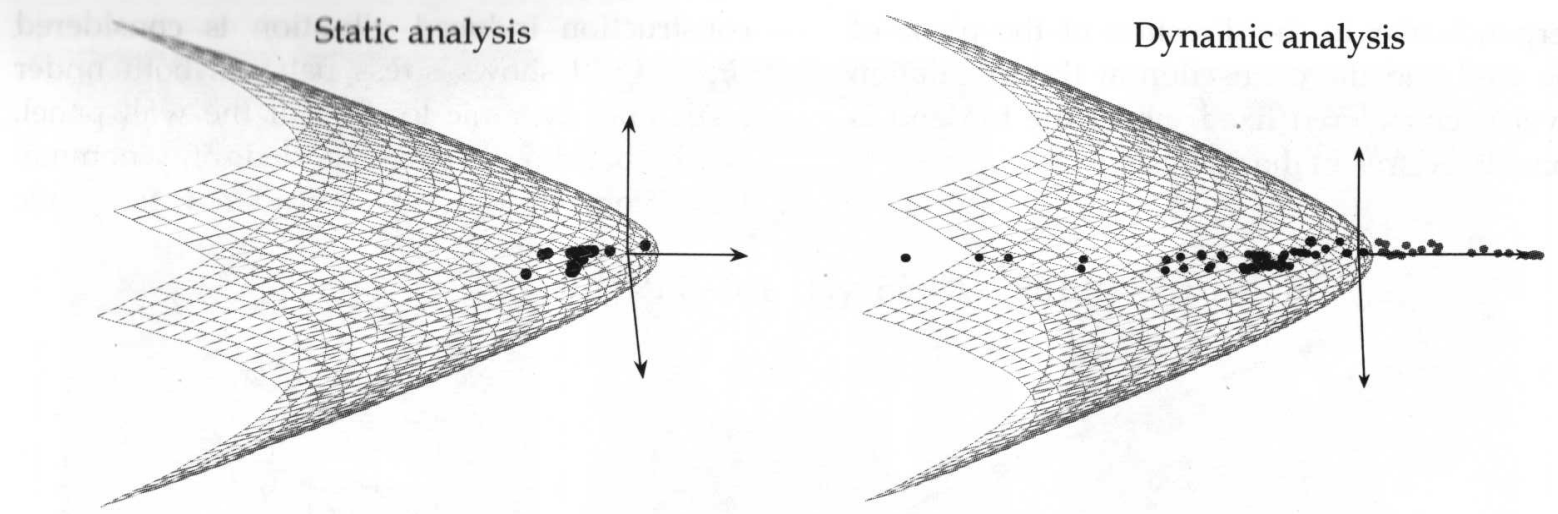

Fig. 10: Resulted stress combinations in the static and dynamic analysis marked with respect to thefailure surface (Solid wall Pannel)

under static and dynamic analysis. In the static analysis stress combinations are located inside the failure surface while under dynamic analysis, some of the stress combinations happen to be outside the failure surface. Furthermore, critical stress pattern under dynamic loading closely match the actual crack pattern of the masonry panel. It is therefore reasonable to assume that the cracking is caused by the vibration. Similar observations were made in the analysis of all the other masonry panels in the study summaries in Fig 2 namely; Fig 11-12 wall with diamond shape fanlight; Fig. 13-14 wall panel with window opening and Fig. 15-16 wall panel with both door and window opening.
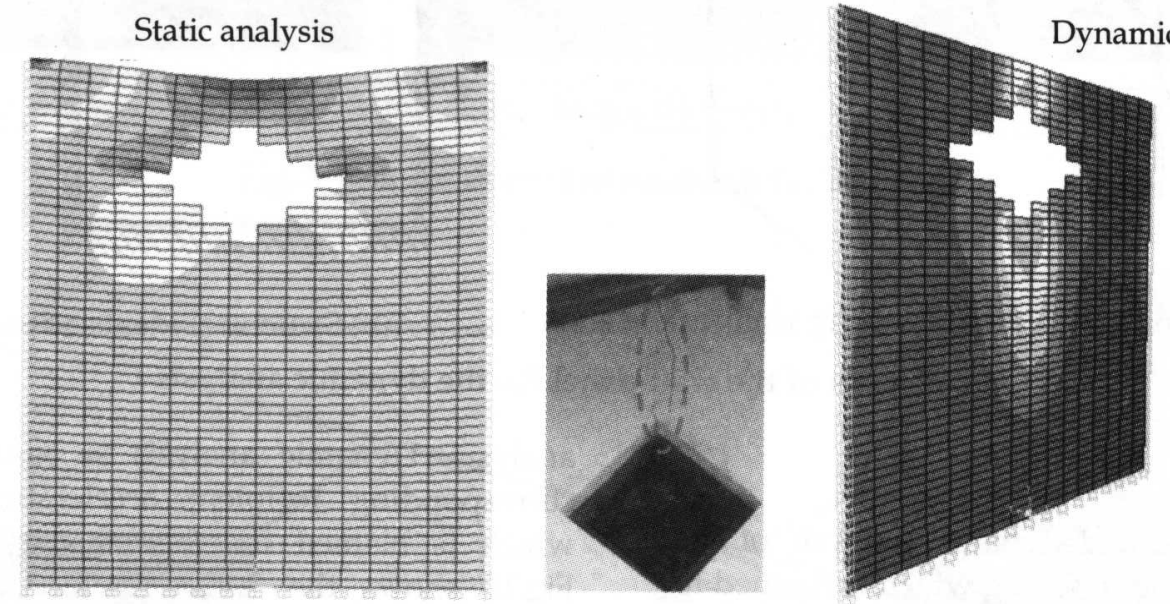

Fig. 11: Principal stresses in the wall panel with diamond shape fanlight under static and dynamic loading (diamond fan light)
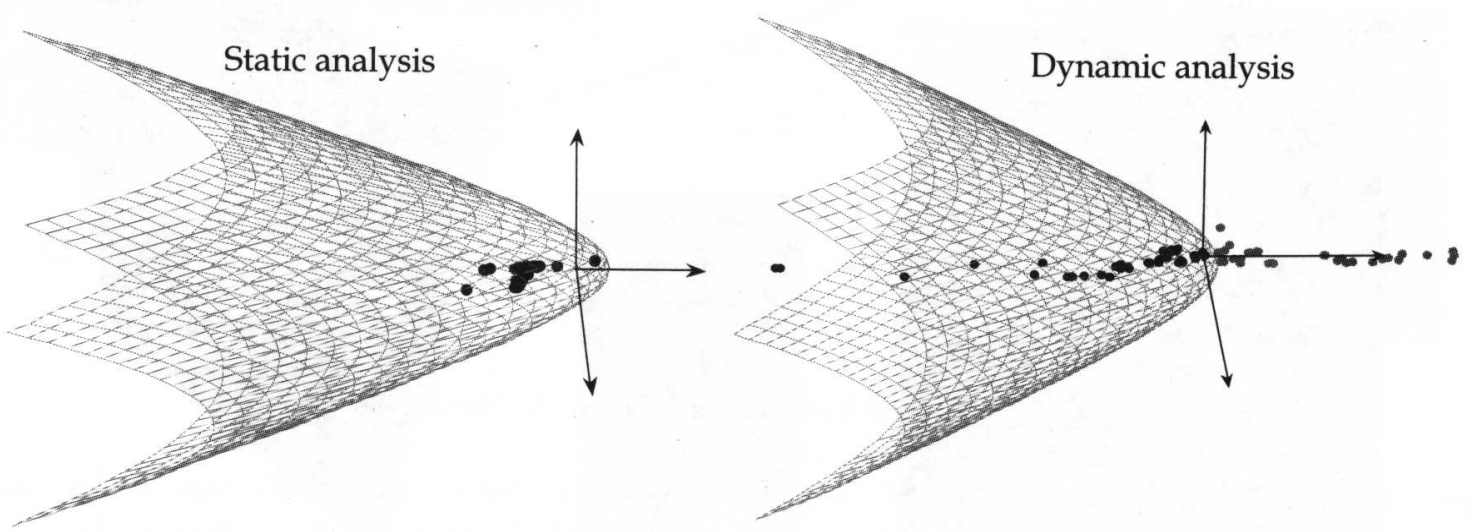

Fig. 12: Resulted stress combinations in the static and dynamic analysis marked with respect to the failure surface (wall panel with diamond opening) 

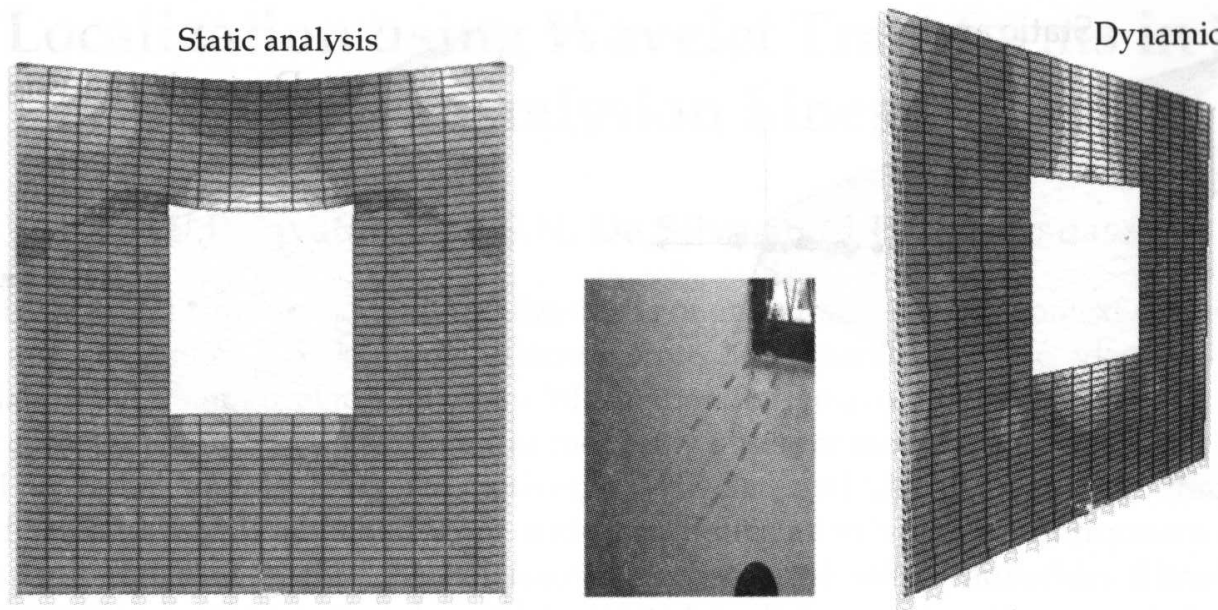

Fig. 13: Principal stresses in the wall panel with window opening under static and dynamic loading (Window opening)
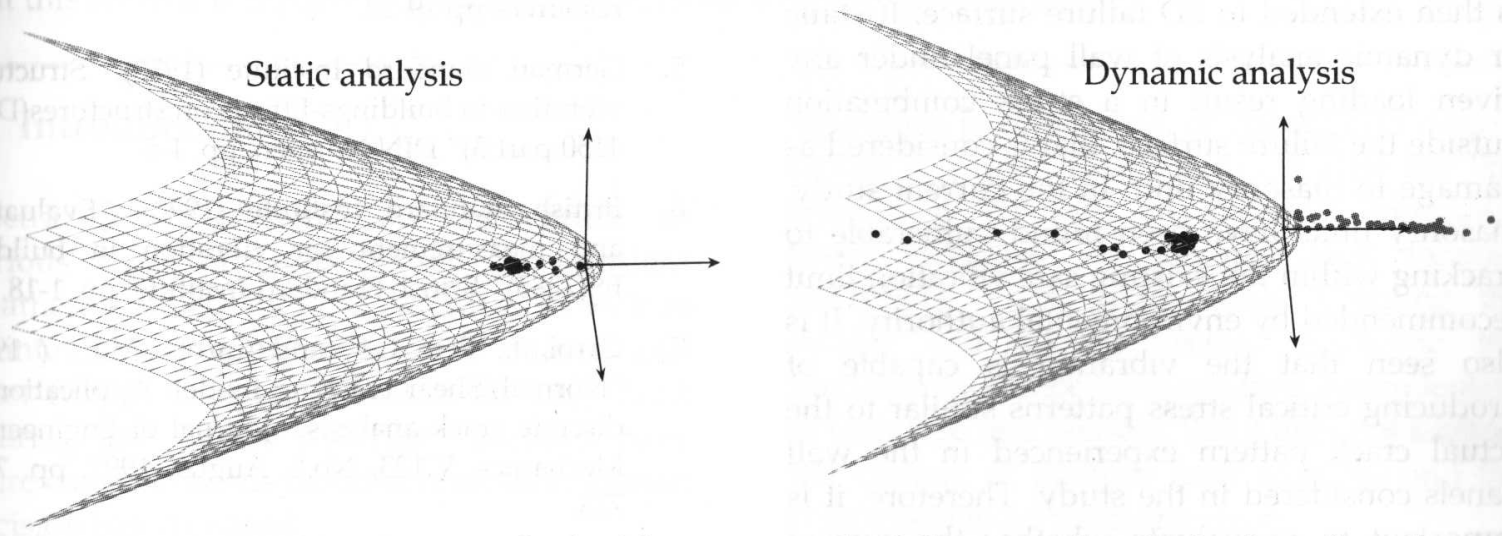

Fig. 14: Stress combinations marked with respect to the failure envelop for both static and dynamic testing (Square opening)
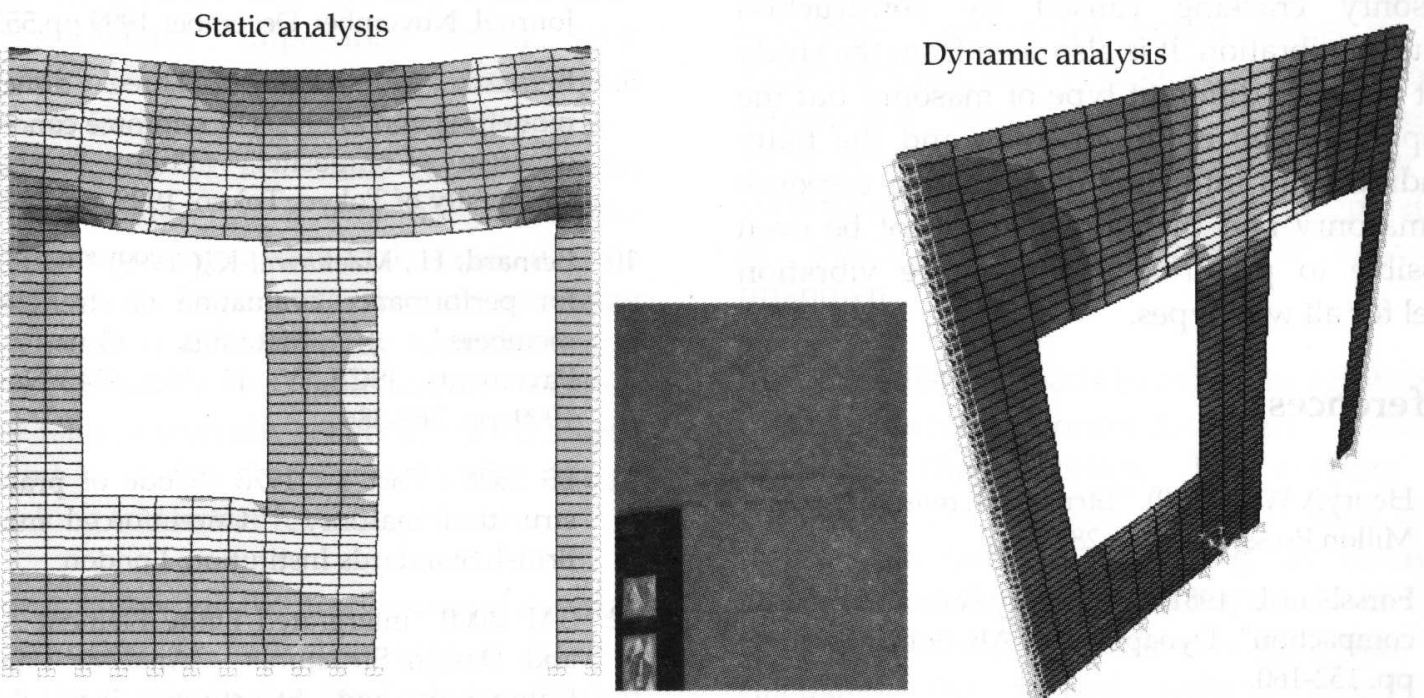

Fig. 15: Principal stresses in the wall panel with door and window openings under static and dynamic loading (door and window openings)

\section{Discussion}

The paper outlines a method that can be used in establishing cracking for local hand moulded burnt clay brick masonry through the establishment of failure surface. Development of failure envelop in $2 \mathrm{D}$ is based on experiments on the interface between the 

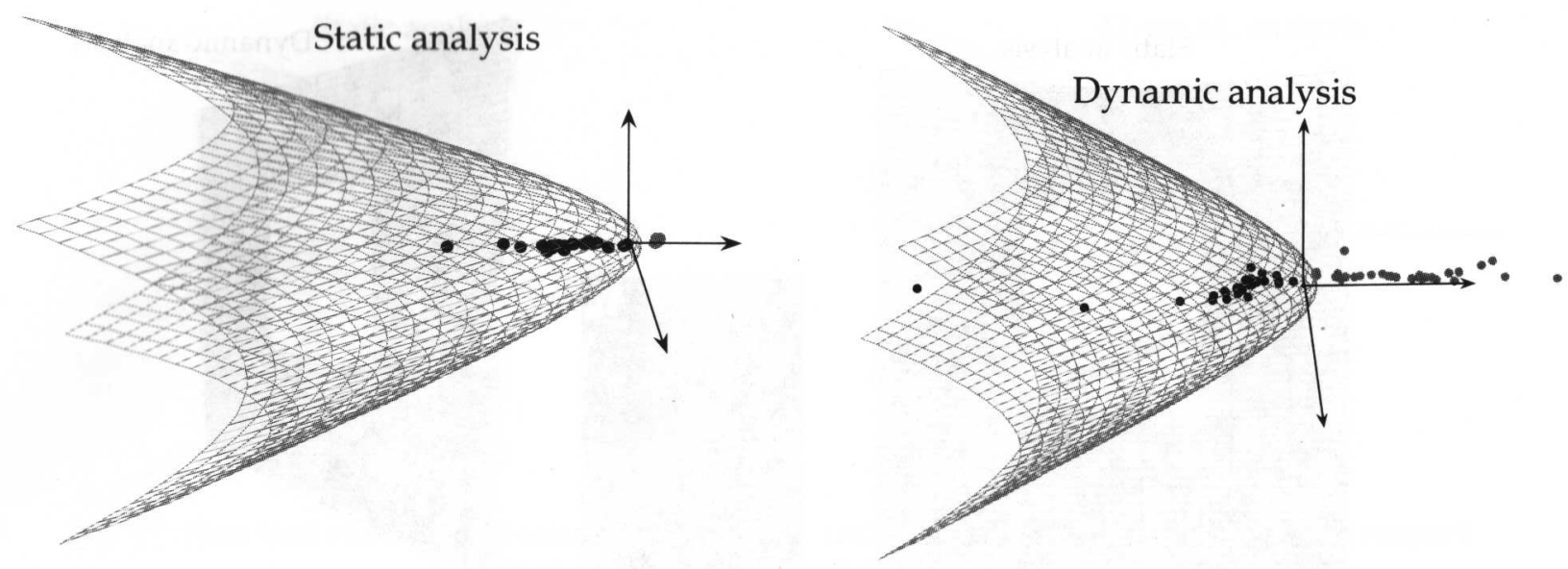

Fig. 16: Stress combinations marked with respect to the failure envelop for both static and dynamic testing (wall panel with door and window opening)

mortar and the brick. The failure envelop in 2D is then extended to 3D failure surface. If static or dynamic analysis of wall panel under any given loading result in a stress combination outside the failure surface, that is considered as damage to masonry unit. In the current study, masonry units have been found vulnerable to cracking within the existing safe vibration limit recommended by environmental authority. It is also seen that the vibration is capable of producing critical stress patterns similar to the actual crack pattern experienced in the wall panels considered in the study. Therefore, it is important to re-evaluate whether the current threshold limit of $2 \mathrm{mms}^{-1}(10-50 \mathrm{~Hz})$ is adequate to safeguard against a possible masonry cracking caused by construction induced vibration. It is also seen from the study that not only different type of masonry but the shape and size of the opening and the fixity condition can influence the dynamic response of masonry and therefore it may not be even possible to prescribe a single safe vibration level for all wall types.

\section{References}

1. HenryA.W., (1990) "Structural masonry, Mac Millon Press, London, 284 pp.

2. Forssblad L (1981), "Vibratory soils and rock fill compaction", Dynap Mskin AB, Solna, Sweden. pp. 152-160.

3. Yegian M.K., Kavaxanjian E., (2004) “Response of cracks to construction vibration and environmental effects", Special geothechnical publication \#126, ASCE, pp 1767-1776

4. Central Environmental Authority (2002) "Interim standards on vibration pollution control" Ministry of Environment and natural resources pp 19-29.

5. German Standard Institute (1975), ‘Structural vibration in buildings-Effects on structures(DIN4150 part 3)" DIN Normen, pp. 1-5

6. British Standard Institute (1990), “Evaluation and measurement for vibration in building BS(7385)" British Standard Institute, pp. 1-18.

7. Carol, I., Pere C.P, and Carols, M.L., ( 1997) "Normal/Shear cracking model: Application to discrete crack analysis," Journal of Engineering Mechanics, V.123, No.8, August 1997, pp. 765773.

8. Abu-Tair, A.I., Rigden, S.R., and Burle, E., (1999), "Testing the bond between repair material and concrete substrate," ACI material Journal, November-December 1999 pp.553-558

9. Bernard, H., (1998), "Three dimensional modelling and analysis of reinforce concrete and concrete Composite," PhD Thesis, The University of Tokyo, Tokyo, 1998, pp.77-79.

10. Bernard, H., Maekawa, K.,( 1999) “3D FEM tool for performance evaluation of strengthen $\mathrm{RC}$ members," J. Materails, Cons. Struct., Pavements, JSCE, V. 45, No. 634, November 1999, pp. 369-386.

11. BS 5628 : Part $1: 1978$, "Code of practice for structural masonry - Unreinforced masonry", British Standards Institution, London.

12. SAP 2000 "Intergrated Finite Element Analysis and Design Structures - Analysis reference", Computers and Structures, Inc., Berkeley, California, USA.

13. Matlab user manual 